\title{
Atypical onset as predictor of poor outcome in Pediatric Systemic Lupus Erythematosus (pSLE)
}

\author{
A Taddio*1, E Rossetto ${ }^{1}$, L Lepore ${ }^{1}$, AC Brescia ${ }^{2}$, C Bracaglia ${ }^{3}$, S Caminiti ${ }^{3}$, \\ E Cortis ${ }^{3}$, D Rigante ${ }^{4}$, A Stabile ${ }^{4}, \mathrm{M} \mathrm{Montico}^{1}$, L Ronfani ${ }^{1}$ and CD Rosé ${ }^{2}$
}

\begin{abstract}
Address: ${ }^{1}$ Institute for Maternal and Child Health - IRCCS Burlo Garofolo, Trieste, Italy, ${ }^{2}$ Division of Rheumatology A.I. duPont Hospital for Children, Department of Pediatrics, Thomas Jefferson University, Wilmington/DE, USA, ${ }^{3}$ Division of Rheumatology, Department of Pediatric Medicine, IRCCS Ospedale Pediatrico Bambino Gesù, Rome, Italy and ${ }^{4}$ Department of Pediatric Sciences, Università Cattolica Sacro Cuore, Rome, Italy

* Corresponding author
\end{abstract}

from $15^{\text {th }}$ Paediatric Rheumatology European Society (PreS) Congress

London, UK. 14-17 September 2008

Published: 15 September 2008

Pediatric Rheumatology 2008, 6(Suppl I):P238 doi:10.1 186/I546-0096-6-SI-P238

This abstract is available from: http://www.ped-rheum.com/content/6/SI/P238

(c) 2008 Taddio et al; licensee BioMed Central Ltd.

\section{Purpose}

Pediatric Systemic Lupus Erythematosus (pSLE) is a multisystem, inflammatory, autoimmune disease. This study is based on the observation that there are limited data on the prognostic factors of children affected by SLE and weak data correlating the course of the disease with its onset. The primary aim of this study is to assess if atypical onset influence the severity of organ damage in pSLE.

\section{Methods}

This is a multicenter IRB-approved chart review. We enrolled all patients affected by pSLE. Medical records were reviewed focusing on clinical features at onset, intended as date of diagnosis and the following 15 days. As atypical onset we meant organ involvement present at onset of pediatric SLE described in literature http:// www.pubmed.com/index, but not included in ACR criteria. The primary outcome was established to be the presence of at least 1 score of System Lupus International Collaborating Clinics/American College of Rheumatology Damage Index for Systemic Lupus Erythematosus (SLICC) ACR). Data on 100 patients were analyzed with multivariate analysis.

\section{Results}

Our population consisted in: 68 Caucasians, 24 AfroAmericans, 5 Latin-Americans and 2 Asians. There were 79 females and 21 males. They were followed up for an aver- age of 5.3 years. $24 \%$ of patients presented aypical clinical features at onset. At multivariate analysis a significant association with outcome variables was showed for the presence at onset of atypical manifestations $(p=0.004)$ and renal involvement $(\mathrm{p}=0.027)$.

\section{Conclusion}

Our data suggest that the presence of renal involvement and atypical manifestations at onset influence the prognosis of patients affected from pSLE. 